\title{
Crescimento e rendimento do abacaxizeiro nas condições climáticas dos Tabuleiros Costeiros do Estado da Paraíba ${ }^{1}$
}

\author{
$\overline{\text { Cleber B. de Souza }^{2} \text {, Bernardo B. da Silva }}{ }^{3}$ \& Pedro V. de Azevedo $^{3}$
}

\begin{abstract}
RESUMO
Um experimento de campo foi conduzido com a cultura do abacaxi, cv. Pérola, em Santa Rita, PB, durante o período março de 2001 a junho de 2002; na ocasião, avaliaram-se o desenvolvimento e o rendimento dessa cultivar, em condições de irrigação suplementar, visando obter informações que possam adequar o manejo da cultura à região. De forma geral, as variáveis de crescimento e rendimento foram compatíveis com o descrito na literatura, destacando-se que o índice de área foliar (IAF) alcançou o valor 12, aos 308 dias após plantio e os frutos com peso acima de 1,7 kg, representaram $60 \%$ do total colhido (57.000 kg). Os frutos de segunda compreenderam 30\% dos frutos colhidos com peso variando de 1,3 a 1,7 kg e os frutos com peso inferior a $1,3 \mathrm{~kg}$, correspondente aos $10 \%$ restantes, foram considerados de qualidade inferior e destinados principalmente à indústria de sucos e rações. O abacaxizeiro, cv Pérola, cultivado com suplementação de irrigação, nas condições de clima e solo dos tabuleiros de Santa Rita, PB, apresentou IAF, tamanho de frutos e rendimento superiores aos obtidos em outras regiões do Brasil, seja em sequeiro ou em condições irrigadas.
\end{abstract}

Palavras-chave: Ananas comosus, análise de crescimento de plantas, produtividade do abacaxizeiro

\section{Growth and yield of pineapple under climatic conditions of the Coastal Table Lands of Paraíba State}

\begin{abstract}
A field experiment was carried out with the pineapple, cultivar Pérola, in Santa Rita in the State of Paraíba, Brazil, during the period from March, 2001 to June, 2002. The development and yield of crop under supplemental irrigation conditions was evaluated in order to obtain information for improving crop management in the region. The growth and yield variables were compatible with those obtained in other studies. The results showed that the leaf area index (LAl) reached a value of 12, 308 days after planting and the fruits with weight above $1.7 \mathrm{~kg}$ reached $60 \%$ of the total harvested fruits. The fruit of $2^{\text {nd }}$ category, with weight between 1.3 and $1.7 \mathrm{~kg}$, represented $30 \%$ of the total fruit production while the remaining $10 \%$ of fruits harvested with weight less than $1.3 \mathrm{~kg}$, were considered of lower quality and sent to the juice and animal food industry. The pineapple crop, cv Pérola, grown under climate and Costal Table Land soil of Santa Rita, PB, presented LAI, size of fruit and yield greater than those obtained in other regions of Brazil, even in irrigated areas.
\end{abstract}

Key words: Ananas comosus, growth analysis, pineapple crop yield

\footnotetext{
1 Parte da Tese de Doutorado em Recursos Naturais/UFCG do primeiro autor

2 DTR/UFPB - 58220-000 Bananeiras, PB. Fone: (83) 3367-1200. E-mail: cleberbrito2004@ig.com.br

${ }^{3}$ UACA/UFCG, Av. Aprígio Veloso 882, Bodocongó, 58109-970, Campina Grande, PB. Fone: (83) 3310-1054. E-mail: bernardo@dca.ufcg.edu.br e pvieira@dca.ufcg.edu.br
} 


\section{INTRODUÇÃO}

De forma consorciada, intercalado ou solteiro, o cultivo do abacaxizeiro nos Tabuleiros Costeiros do estado da Paraíba, vem melhorando a economia local e alterando o panorama agrícola daquelas áreas. O cultivo comercial do abacaxizeiro (Ananas comosus) tem-se limitado às cultivares Pérola, Jupi e Smooth Cayenne, das quais o estado da Paraíba é tradicional fornecedor de frutas e de mudas para outros estados brasileiros, através de produtores selecionados que adotam tecnologias de bom nível empresarial, tanto na agricultura de sequeiro quanto nas áreas irrigadas, condição que o destaca como um dos maiores produtores nacionais e o de melhor qualidade (Barreiro Neto et al., 1998).

A cultivar Pérola, apesar de sua importância econômica para o País, especialmente no estado da Paraíba, tem sido pouco pesquisado com relação ao seu desenvolvimento vegetativo e reprodutivo, sobretudo quando associada a aspectos da irrigação e variáveis agrometeorológicos; entretanto, Reinhardt \& Medina (1992) e Barreiro Neto et al. (1998) conduziram estudos com essa cultivar em diferentes regiões do Brasil visando à caracterização de padrões do sistema produtivo em campos comerciais e à melhor utilização ou aproveitamento do fruto, tanto na forma in natura, como para a industrialização. Cunha \& D’Oliveira (1993), Cunha \& Rocha (1993) e Barreiro Neto et al. (1998) ao descreverem a cultivar Pérola destacam, como principais atributos: o peso do fruto, entre 1,0 e $1,5 \mathrm{~kg}$, o sabor menos ácido que o da cultivar Smooth Cayenne e o grande número de filhotes.

Através da técnica da análise de crescimento se expressam os vários parâmetros de crescimento da planta (Aguiar Neto et al., 1999; Silva et al., 2000; Razzaque \& Hanafi, 2001; Reinhardt et al., 2002; Oliveira et al., 2005). Esses conhecimentos sobre o crescimento da planta são fundamentais para seu manejo adequado e a identificação de problemas no desenvolvimento da cultura, tais como: ocorrência de deficiências hídrica e nutricional, competição de plantas daninhas, solos compactados ou mal drenados, entre outros (Reinhardt \& Medina, 1992; Barreiro Neto et al., 1998).

Face à grande importância da cultura do abacaxi para o estado da Paraíba, este trabalho objetivou a avaliação do crescimento, desenvolvimento e rendimento dessa Bromeliácea cultivada em condições de suplementação de irrigação, nas condições de clima e solo dos tabuleiros de Santa Rita, PB.

\section{MATERIAL E MÉTODOS}

Um experimento de campo foi conduzido no sítio Senhor do Bonfim, na localidade Mumbaba de Belê, no município de Santa Rita, PB, com coordenadas $7^{\circ} 14^{\prime} 20^{\prime \prime}$ S e $34^{\circ} 59^{\prime} 28^{\prime \prime} \mathrm{W}$ e $85 \mathrm{~m}$ de altitude, no período de 23/3/2001 a 27/6/2002. De acordo com a classificação climática de Köppen, o clima da região é do tipo As' - quente e úmido, em que o período das chuvas ocorre nas estações de verão e outono. Valores médios diários obtidos a partir de instrumentos meteorológicos colocados no interior da área experimental, no período de $10 / 08 / 2001$ a 27/06/2002, permitiram caracterizar, por fases do cultivo, as condições meteorológicas do local do experimento, em termos de temperatura do ar, umidade relativa do ar, velocidade do vento e radiação solar (Tabela 1), enquanto os valores das precipitações pluviométricas e das irrigações mensais são apresentados na Tabela 2; as irrigações totalizaram $191 \mathrm{~mm}$, resultando num consumo hídrico de 1.647,0 mm para o ciclo da cultura.

Tabela 1. Valores médios diários da temperatura do ar (Ta), umidade relativa do ar (UR), velocidade do vento (V) e radiação solar à superfície $\left(\mathrm{R}_{\mathrm{s}}\right)$ para cada fase do cultivo do abacaxizeiro cv. Pérola, em Santa Rita, PB, 2001/2002

\begin{tabular}{|c|c|c|c|c|c|c|c|c|}
\hline \multirow{2}{*}{ Fases do cultivo } & \multicolumn{3}{|c|}{$\mathrm{T}_{\mathrm{a}}\left({ }^{\circ} \mathrm{C}\right)$} & \multicolumn{3}{|c|}{ UR (\%) } & \multirow{2}{*}{$\begin{array}{c}\mathbf{V} \\
\left(\mathrm{m} \mathrm{s}^{-1}\right)\end{array}$} & \multirow{2}{*}{$\begin{array}{c}R_{s} \\
\left(\mathrm{MJ} \mathrm{m}^{-2}\right)\end{array}$} \\
\hline & $\min$ & $\max$ & med & $\min$ & $\max$ & med & & \\
\hline $\begin{array}{l}\text { Desenvolvimento } \\
\text { vegetativo }\end{array}$ & 21,3 & 31,0 & 26,2 & 50,5 & 94,0 & 72,3 & 1,96 & 21,28 \\
\hline $\begin{array}{l}\text { Florescência } \\
\text { Queda de flores }\end{array}$ & 22,5 & 32,5 & 27,5 & 56,7 & 93,9 & 75,3 & 1,84 & 20,86 \\
\hline Formação do fruto & 22,2 & 30,9 & 26,6 & 62,8 & 94,3 & 78,6 & 1,89 & 17,13 \\
\hline Colheita & 21,5 & 28,8 & 25,2 & 62,8 & 94,3 & 78,8 & 1,98 & 14,51 \\
\hline Ciclo total & 21,8 & 31,2 & 26,5 & 52,5 & 94,2 & 73,4 & 1,92 & 19,98 \\
\hline
\end{tabular}

A parcela experimental, com 90 × $90 \mathrm{~m}$, possui topografia plana circundada por uma grande área plantada com abacaxi minimizando, desta forma, os efeitos advectivos. O solo é do tipo Neossolo (EMBRAPA, 1999), profundo, textura francoarenoso, boa drenagem, com pH 4,35. Embora o solo da área tenha apresentado alto valor de acidez, porém baixo em alumínio $(0,80)$, não foram efetuadas correções de solo. Reconhece-se que o abacaxizeiro se desenvolve melhor em solos ácidos indicando-se, normalmente, a faixa de $\mathrm{pH}$ de 4,5 a 5,5 como a mais recomendada; entretanto, admite-se que o mesmo pode ser cultivado em solos com $\mathrm{pH}$ abaixo de 4,5 o que, dependendo da variedade, não chega a comprometer a sua produção (Souza, 1999). A água utilizada na suplementação da irrigação do abacaxizeiro foi proveniente de um poço amazonas, classificada como $\mathrm{C}_{1}$ e adequada ao uso da irrigação e baixo risco de salinização dos solos (Ayers \& Westcot, 1991). As plantas (mudas tipo filhotes) provieram de campos comerciais de produção, anexos ao local do experimento, de bom nível de sanidade, apresentando peso entre 300 a $500 \mathrm{~g}$ e comprimento de 40 a $50 \mathrm{~cm}$. O preparo do solo constou de duas passagens cruzadas, efetuadas com grade aradora. Posteriormente, abriram-se sulcos para o plantio, que ocorreu em 23/03/2001. O espaçamento foi de 0,80 x 0,25 m (50.000 plantas $\mathrm{ha}^{-1}$ ) e nas adubações foram utilizados os seguintes percentuais de N, P e K: $16-8-24$, correspondendo a Uréia 3,5 g por planta; Superfosfato Triplo - 2,0 g por planta; Cloreto de Potássio 3,5 g por planta (adubação inicial aplicada aos 95 dias após plantio - DAP); Uréia - 4,5 g por planta; Cloreto de Potássio 5,0 g por planta (aplicada aos 251 DAP) e $500 \mathrm{~kg} \mathrm{ha}^{-1}$ formulação 22 - 0 - 29, aplicada aos 390 DAP. Aplicou-se, também, como adubação complementar, sulfato de cobre $\left(3,0 \mathrm{~kg} \mathrm{ha}^{-1}\right)$, sulfato de zinco $\left(3,0 \mathrm{~kg} \mathrm{ha}^{-1}\right)$, bórax (4,0 $\mathrm{kg} \mathrm{ha}^{-1}$ ) e 5 ton ha- ${ }^{-1}$ de composto orgânico (cama-de-galinha). Os tratos culturais e fitossanitários foram efetuados de acordo com as necessidades do cultivo. A indução floral ocorreu 
Tabela 2. Valores mensais de precipitação pluviométrica (Pr) e irrigações (I), obtidos na área do experimento em Santa Rita, PB, para os anos de 2001 e 2002

\begin{tabular}{|c|c|c|c|c|}
\hline \multirow{2}{*}{ Meses } & \multicolumn{2}{|c|}{ Ano 2001} & \multicolumn{2}{|c|}{ Ano 2002} \\
\hline & $\operatorname{Pr}(\mathrm{mm})$ & I (mm) & $\operatorname{Pr}(\mathrm{mm})$ & $\mathrm{I}(\mathrm{mm})$ \\
\hline Janeiro & - & - & 123,2 & - \\
\hline Fevereiro & - & - & 114,1 & - \\
\hline Março & 37,3 & - & 169,3 & 14,5 \\
\hline Abril & 167,9 & - & 48,1 & - \\
\hline Maio & 23,3 & - & 129,8 & - \\
\hline Junho & 113 & - & 256,3 & - \\
\hline Julho & 107 & - & - & - \\
\hline Agosto & 35,4 & - & - & - \\
\hline Setembro & 35,2 & 30,6 & - & - \\
\hline Outubro & 15,9 & 71,5 & - & - \\
\hline Novembro & 24,8 & 46,3 & - & - \\
\hline Dezembro & 48,8 & 28,1 & - & - \\
\hline
\end{tabular}

em 25/1/2002, isto é, 10 meses após o plantio, efetuada à base de carbureto de cálcio (granulado: 0,5 a 1 g por planta) colocada na roseta foliar das plantas, via funil, no horário entre 5 e $9 \mathrm{~h}$ (tempo local). A colheita dos frutos teve início em 08/ 06/2002, 135 dias após a indução floral, quando os frutos apresentavam cor amarela em alguns frutilhos - fase imaturo para semi-maturo.

Para suplementação da irrigação aplicaram-se lâminas de irrigação de 2,0 $\mathrm{mm} \mathrm{d}^{-1}$, baseadas em médias usadas pelos irrigantes de abacaxi daquela região; assim, uma lâmina de 14 mm era aplicada de 7 em 7 dias, sempre que não ocorressem precipitações no período, o que foi suficiente para manter a cultura livre de estresse hídrico. Para a irrigação, utilizou-se um sistema por aspersão móvel, com canos de diâmetro de $75 \mathrm{~mm}$ na linha principal e $50 \mathrm{~mm}$ na linha de derivação e aspersores instalados em canos de subida de $25 \mathrm{~mm}$ com $1 \mathrm{~m}$ de altura, cujas especificações técnicas são: bocal de 5,6 x 3, $2 \mathrm{~mm}$, com precipitação de $30 \mathrm{~mm}$ e vazão de $2,66 \mathrm{~m}^{3} \mathrm{~h}^{-1}$. O volume de água aplicado na parcela experimental foi quantificado via hidrômetro, disposto na entrada de cada linha secundária de irrigação. Na parte central da área experimental escolheu-se uma sub-área de 10 x 10 m, com aproximadamente 500 plantas, dentre as quais foram marcadas 20 plantas ao acaso, destinadas às medições de altura e diâmetro de caule de cada planta. De acordo com a média de dados da altura e diâmetro dessas plantas escolhidas selecionaram-se, aleatoriamente, fora dessa sub-parcela, 3 plantas que representassem visualmente as mesmas características daquelas plantas da sub-parcela, a intervalos de 4 semanas, para determinação da biomassa fresca e seca, e do índice de área foliar. Tais medições foram iniciadas a partir de 19/5/2001, quando a cultura se encontrava totalmente estabilizada e iniciando a fase de crescimento vegetativo. Antes da coleta dessas plantas foram medidas, com fita métrica graduada em milímetros, as variáveis: altura e diâmetro da planta, além do diâmetro e altura de inserção do pedúnculo. Após limpeza, as plantas tiveram suas partes separadas em folhas, caule, pedúnculo, filhotes e fruto, descartando-se as raízes; em seguida, foram pesadas e acondicionadas em saco de papel e colocadas em estufa a $65^{\circ} \mathrm{C}$, até atingirem peso constante. A área foliar foi obtida com um integrador de área foliar, modelo LI-3000 da
LI-COR. Foram também contabilizados o número e comprimento de folhas, comprimento e diâmetro do caule, comprimento e diâmetro do pedúnculo, número e comprimento do filhote, comprimento do fruto com coroa, sem coroa e comprimento da coroa, diâmetro médio do fruto com casca, número de frutilhos, diâmetro do coração, SST (Brix) e acidez.

A partir da matéria seca total, obtiveram-se os seguintes índices fisiológicos (Silva, 2000): Taxa de Crescimento da Cultura (TCC), Taxa de Crescimento Relativo (TCR) e Taxa de Assimilação Líquida (TAL), calculados segundo as expressões:

$$
\begin{gathered}
\mathrm{TCC}=\left(\mathrm{P}_{2}-\mathrm{P}_{1}\right) /\left(\mathrm{T}_{2}-\mathrm{T}_{1}\right)\left(\mathrm{g} \mathrm{d}^{-1}\right) \\
\mathrm{TCR}=\left(\ln _{2}-\ln \mathrm{P}_{1}\right) /\left(\mathrm{T}_{2}-\mathrm{T}_{1}\right)\left(\mathrm{g} \mathrm{g}^{-1} \mathrm{~d}^{-1}\right) \\
\mathrm{TAL}=\left(\mathrm{P}_{2}-\mathrm{P}_{1}\right) \times\left(\ln \mathrm{A}_{2}-\ln \mathrm{A}_{1}\right) /\left(\mathrm{T}_{2}-\mathrm{T}_{1}\right) \times\left(\mathrm{A}_{2}-\mathrm{A}_{1}\right)
\end{gathered}
$$

donde $\mathrm{P}_{1}$ e $\mathrm{P}_{2}$ representam o peso da matéria seca $(\mathrm{g})$ de duas amostragens sucessivas em intervalos de tempo $T_{1}$ e $T_{2}$ (quatro semanas) e $\mathrm{A}_{1}$ e $\mathrm{A}_{2}$, compreendem a área foliar $\left(\mathrm{m}^{2}\right)$ média das plantas coletadas nos dias $\mathrm{T}_{1}$ e $\mathrm{T}_{2}$.

$\mathrm{O}$ índice de área foliar (IAF) foi determinado pela razão entre a área foliar total (AF) em $\mathrm{m}^{2}$, média de 3 plantas e a área do solo correspondente à amostra $\left(\mathrm{m}^{2}\right)$ :

$$
\mathrm{IAF}=\mathrm{AF} / \mathrm{As}
$$

donde $\mathrm{As}\left(\mathrm{m}^{2}\right)$ é a área sombreada por cada planta.

A classificação dos frutos colhidos foi efetuada segundo os padrões de recomendações metodológicas descritas por Vilar (2000).

Para as avaliações acima descritas, o ciclo vegetativo do abacaxizeiro foi dividido nas seguintes fases: 1) inicial: 56 dias (23/3 a 18/5/2001), tempo necessário ao estabelecimento das mudas; 2) crescimento vegetativo: 252 dias (19/5/2001 a 25/1/ 2002), período marcado pela formação do caule e das folhas; 3) florescência/queda de flores: 70 dias, sendo que no estágio de florescência: 42 dias $(26 / 1$ a 8/3/2002) e no de queda de flores: 28 dias $(9 / 3$ a 4/4/2002); 4) formação do fruto: 75 dias (5/4 a 18/06/2002); 5) colheita: a partir de 18/6/2002.

\section{RESULTADOS E DISCUSSÃO}

A altura das plantas (h, em $\mathrm{cm}$ ) atingiu o valor máximo de $115 \mathrm{~cm}$ aos 308 dias após plantio (DAP), podendo ser estimada em função dos DAP como: $h(\mathrm{~cm})=-0,0004$. DAP ${ }^{2}+$ 0,4226.DAP $+19,154$, com $\mathrm{R}^{2}=0,9467$ (Figura 1A). Os relatos encontrados na literatura descrevem que uma planta adulta, crescendo em condições climáticas ideais e sem deficiência hídrica, atinge 100 a $120 \mathrm{~cm}$ de altura. Em condições de sequeiro, Reinhardt \& Medina (1992) obtiveram altura de plantas da ordem de 81 a $93,5 \mathrm{~cm}$ e $97 \mathrm{~cm}$, respectivamente.

A variação do diâmetro média das plantas, comprimento e diâmetro do caule é apresentada na Figura 1B. O diâmetro das plantas pode ser estimado pela equação de regressão: $\mathrm{Dp}=$ 0,0001.DAP ${ }^{2}+0,2562$.DAP $+17,285$, com $\mathrm{R}^{2}=0,9334$; no período de 56 aos 196 DAP, verificou-se uma expansão de 3 a 5 $\mathrm{cm}$, entre uma e outra medição, alcançando 5 a $9 \mathrm{~cm}$ no perí- 
A.

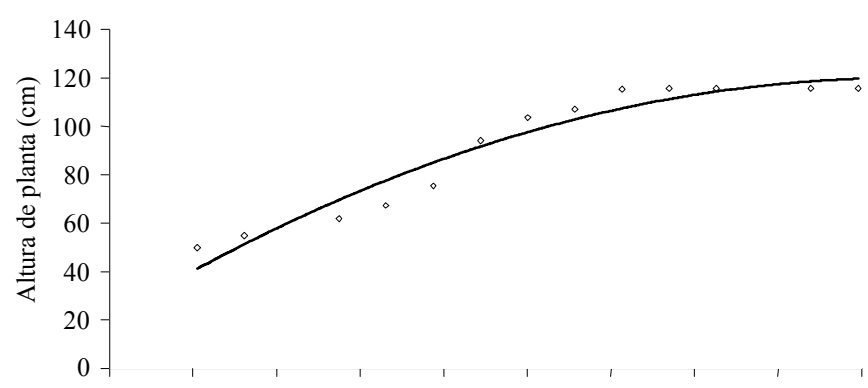

B.

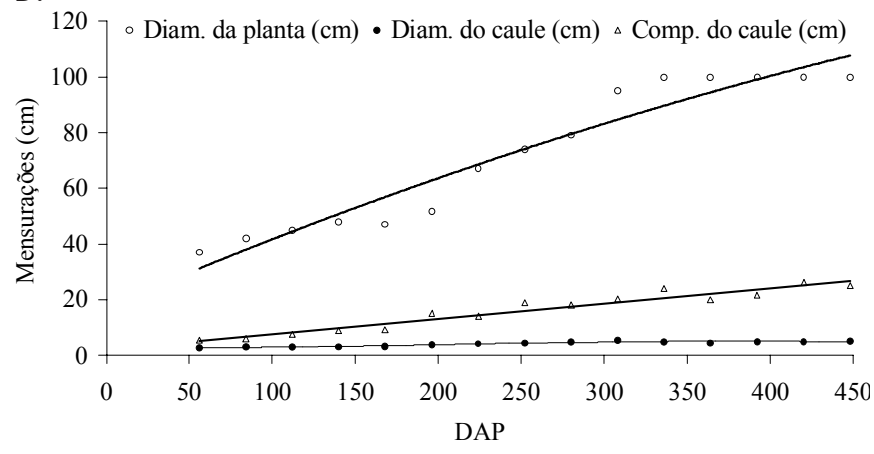

Figura 1. A. Altura das plantas; B. Diâmetro médio da planta, diâmetro e comprimento do caule da planta, durante as fases de crescimento e desenvolvimento do cultivo do abacaxizeiro, cv. Pérola. Sítio Senhor do Bonfim, Santa Rita, PB, 2001/2002

odo entre 196 e 280 DAP. O maior valor foi obtido por volta dos 336 DAP $(100 \mathrm{~cm})$, mantendo-se constante a partir de então. Associa-se esta manutenção de diâmetro das plantas após os 336 DAP ao espaçamento utilizado, que não permitiu uma expansão lateral maior das mesmas. Relatos encontrados na literatura sobre abacaxi, citam ocorrências de diâmetro de planta variando de 130 a $150 \mathrm{~cm}$. Barreiro Neto et al. (1998), traçando um perfil da cultivar Pérola, no Estado da Paraíba, encontraram para o diâmetro de plantas, valores médios de $75,9 \mathrm{~cm}$. Em espaçamentos adensados, combinando altura de plantas superior a $100 \mathrm{~cm}$ e diâmetro de planta inferior a 80 $\mathrm{cm}$, principalmente em áreas irrigadas, observou-se que, após os 240 DAP, os tratos culturais, tratamentos fitossanitários, tratamento de indução floral (TIF) e manejos de irrigação, são executados com maior dificuldade e de forma mais lenta ocorrendo, em alguns casos, danos às plantas, o que está de acordo com as afirmações de Cunha (1999).

As equações de regressão do comprimento do caule $\left(\mathrm{C}_{\mathrm{c}}=\right.$ $0,055 \cdot \mathrm{DAP}+2,1526)$ e diâmetro do caule $\left(\mathrm{D}_{\mathrm{c}}=-1 \times 10^{-7} \cdot \mathrm{DAP}^{3}+\right.$ $7 \times 10^{-5}$.DAP ${ }^{2}-0,0035$.DAP + 2,7016) em função dos DAP, proporcionaram coeficientes de determinação de 0,9347 e 0,8947, respectivamente (Figura 1B). Esses valores crescentes indicam o armazenamento de metabólitos da fotossíntese pelo caule com o passar dos dias, especialmente a partir dos 196 DAP, ocasionado pelo aumento do número de folhas e altura da planta (Cunha \& Cabral, 1999). Plantas adultas apresentam comprimento do caule $\left(\mathrm{C}_{\mathrm{c}}\right)$ entre 20 e $35 \mathrm{~cm}$ e diâmetro do caule $\left(D_{c}\right)$ entre 2,0 e $3,5 \mathrm{~cm}$ na parte basal e entre 5,5 e 7,0 $\mathrm{cm}$ na parte mais larga, logo abaixo do ápice (Cunha, 1999, Coppens D'eeckenbrugge \& Leal, 2003). Neste estudo, foi considerado um diâmetro médio para todo o caule; desta for- ma, aos 308 DAP o caule apresentou maior diâmetro, $5,5 \mathrm{~cm}$; o maior comprimento, $\mathrm{C}_{\mathrm{c}}=26,17 \mathrm{~cm}$, só foi alcançado aos 420 DAP. Uma vez que a cultura não sofreu deficiência de água, luz e nutrientes, o não acompanhamento do maior diâmetro ao maior comprimento pode ser característica da planta e/ou cultivar analisada. Mesmo assim, os valores de diâmetro e comprimento do caule estão dentro das análises das características da cultivar Pérola.

A caracterização do cultivo compreendeu a análise entre o 56 a 448 DAP. Desta forma, encontra-se representado na Figura 2A o comportamento da fitomassa fresca total (FFT) e da fitomassa seca total (FST). Os maiores valores obtidos na fase de crescimento vegetativo do cultivo, foram 3.170 e 411 $\mathrm{g}$, respectivamente, para FFT e FST. As médias dessa fase do cultivo foram, então, de 1.343,56 g (FFT) e de 171,10 g (FST), respectivamente e, após o tratamento da indução floral (TIF), 4.024 g para FFT e 555,96 g para a FST mostrando, então, na fase seguinte (florescência/queda de flores), a in-
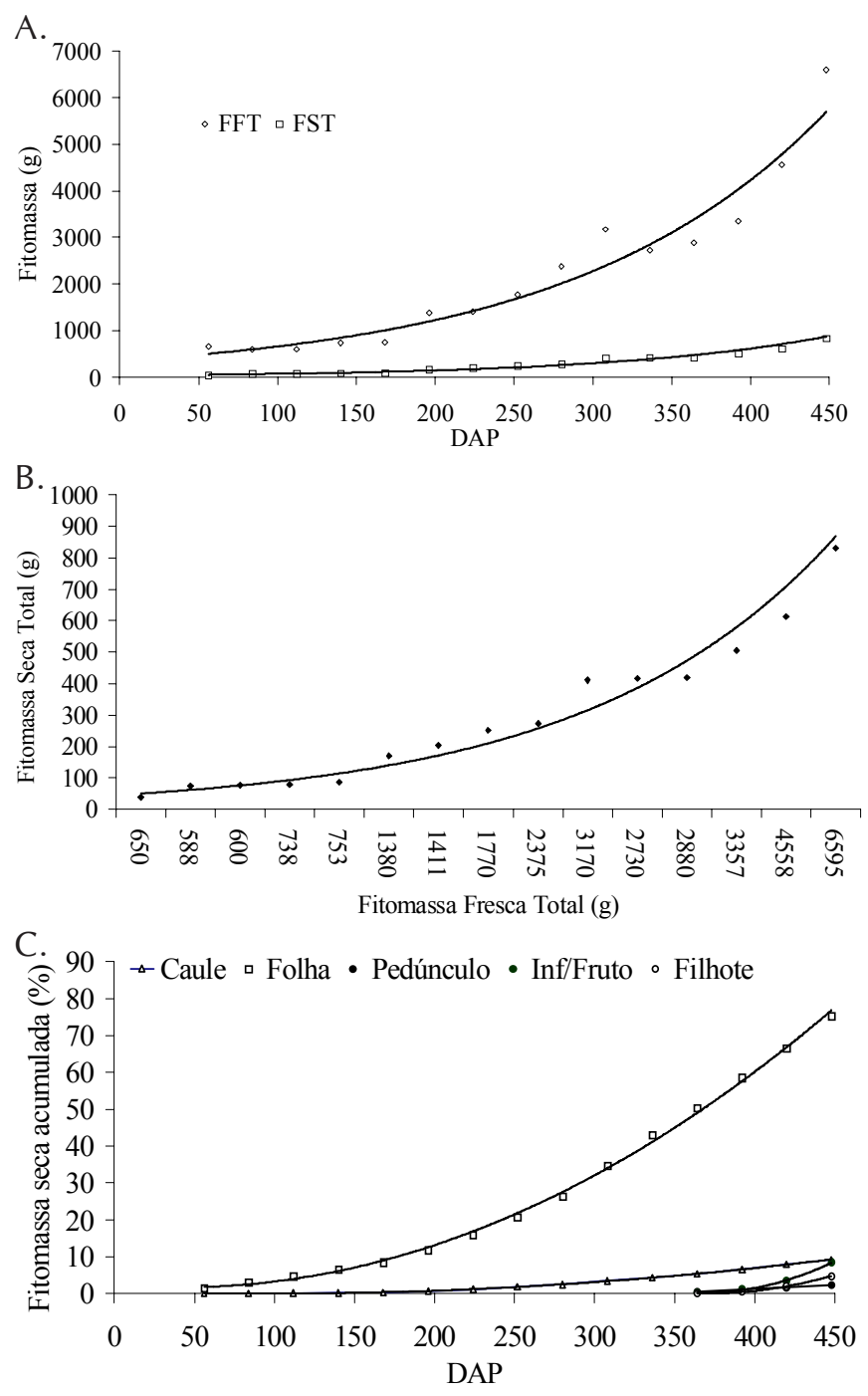

Figura 2. A. Comportamento da Fitomassa Fresca Total (FFT) e da Fitomassa Seca Total (FST) com os DAP; B. relação entre a Fitomassa Total e Fitomassa Fresca Total; e C. Fitomassa Seca Acumulada, em termos percentuais, em função de cada órgão da planta do abacaxizeiro, com os DAP, ao longo da estação de cultivo do abacaxizeiro, cv. Pérola, Sítio Senhor do Bonfim, Santa Rita, PB, 2001/ 2002 
fluência do acréscimo de peso do pedúnculo, inflorescência/ fruto e filhotes no ganho de peso de FST em relação à fase de crescimento vegetativo do cultivo.

De acordo com Malézieux et al. (2002), o acúmulo de matéria seca fixada pelo abacaxi é superior ao do trigo (18 a $29 \mathrm{t}$ $\mathrm{ha}^{-1}$ ano $\left.^{-1}\right)$ e inferior ao da cana-de-açúcar $\left(67 \mathrm{t} \mathrm{ha}^{-1} \mathrm{ano}^{-1}\right)$. Neste estudo, a acumulação de massa seca no fruto alcançou 41,5 t ha-1. Este acúmulo de matéria seca pelo abacaxi está associado aos elevados valores alcançados pelo índice de área foliar (IAF) e à habilidade das folhas em manter a capacidade fotossintética prolongada por um longo período de tempo (Malézieux et al., 2002). Tanto a FFT quanto a FST estiveram fortemente relacionadas com os DAP, cujas equações de regressão $(\mathrm{FFT}=354,35 \exp (0,0062$.DAP $)$ e FST $=$ $34,033 \exp (0,0072$.DAP) $)$, resultaram em coeficientes de determinação de 0,9535 e 0,9635 , respectivamente (Figura 2A).

Ao longo das fases do cultivo, a FFT apresentou-se fortemente relacionada com a FST, conforme a regressão: FFT = 41,67. $\exp ^{0,3025 .(F S T)}$, com $\mathrm{R}^{2}=0,9635$ (Figura 2B). Estes resultados obtidos, indicam a quantidade de água retida pelas plantas nas diversas fases de desenvolvimento em relação ao que as plantas possam, potencialmente, converter em matéria seca. Valores da fitomassa seca acumulada (FSA) para os diferentes órgãos da planta do abacaxizeiro, estão representados na Figura 2C. Para todas as partes da planta, a FSA esteve fortemente relacionada com os dias após o plantio: caule $\left(\mathrm{R}^{2}=\right.$ 0,9993), folha $\left(\mathrm{R}^{2}=0,9982\right)$, pedúnculo $\left(\mathrm{R}^{2}=0,9996\right)$, inf/fruto $\left(\mathrm{R}^{2}=0,9958\right)$ e filhote $\left(\mathrm{R}^{2}=0,9999\right)$.

O maior valor absoluto em percentual de FST por órgão foi: folhas $75,23 \%$, caule $9,72 \%$, frutos $8,45 \%$, filhotes $4,81 \%$ e pedúnculo $2,27 \%$. De acordo com esses percentuais apresentados por órgãos, o sistema fotoassimilador das folhas foi o que mais contribuiu para o ganho percentual de FST. Comparando-se os dados obtidos entre FST por caule e FST por fruto, observa-se ligeira superioridade da FST caule ${ }^{-1}$ em relação a FST por fruto e, deste, apresentando-se duas vezes maior que a FST por filhotes e quatro vezes maior que a do pedúnculo. Zhang \& Bartholomew (1997) obtiveram, durante a fase vegetativa da cv. Smooth Cayenne, cerca de $87 \%$ de FST para as folhas e $13 \%$ para o caule. Os resultados acima indicam que, independente da cultivar de abacaxi, os maiores ganhos em FST são obtidos pelas folhas, resultante das suas habilidades em manter a capacidade fotossintética prolongada por um longo período de tempo (Malézieux et al., 2002).

O comportamento por órgão individualizado de FFT e FST pode ser observado na Figura 3 (A e B). Independente das variações associadas a cada órgão específico, constata-se que na $1^{\text {a }}$ fase do cultivo as folhas (Figura $3 \mathrm{~A}$ ) foram as maiores responsáveis pelo ganho total de peso das plantas. Como característica básica das Bromeliáceas, a parte aérea é formada essencialmente pelas folhas, as quais são expostas a uma atividade fotossintética maior. De acordo com a Figura 3B, os valores médios de FFT e FST mensal do pedúnculo, inflorescência/fruto e filhotes, foram de 212,10 e 25,53 g; 817,10 e 94,96 g; 445,42 e 54,03 g, respectivamente, o que em termos percentuais, a FST do pedúnculo representou $26,8 \%$ em relação a FST do fruto e 47,2\% em relação à fitomassa do filhote. Conclui-se, assim, que valores aproximados a 2/3 e 1/2 da FST
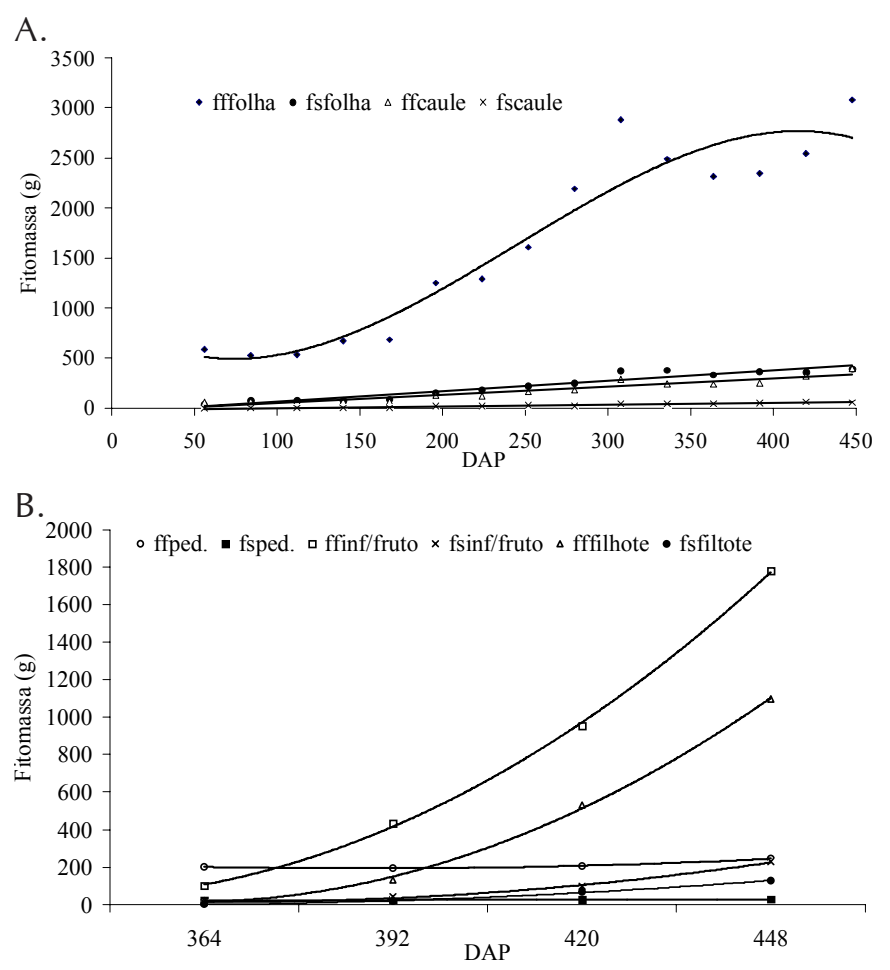

Figura 3. Fitomassa total fresca e seca do caule e da folha do abacaxizeiro, cv. Pérola ao longo da estação de cultivo (A) e Fitomassa fresca e seca do pedúnculo, inflorescência/fruto e filhotes do abacaxizeiro durante a fase de produção (B). Sítio Senhor do Bonfim, Santa Rita, PB, 2001/2002.

do fruto e do filhote, respectivamente, representam cargas extras suportadas pelo pedúnculo, mostrando sua importância, em termos de suporte e distribuição mecânica de peso à sustentação de outro órgão; no caso, o próprio fruto.

$\mathrm{Na}$ Tabela 3 se encontra o resultado médio de diferentes características de 3 plantas, obtido por ocasião da última coleta, enquanto na Tabela 4 se compararam variáveis da planta do abacaxizeiro obtidas, neste experimento, com variáveis oriundas de outros municípios do Brasil.

Os dados apresentados na Tabela 4 evidenciam uma diferenciação de valores do peso do fruto da área experimental em Santa Rita, PB, em comparação com aqueles obtidos para outras localidades, tanto em condições de irrigação quanto em condições de sequeiro. Em geral, a produtividade do abacaxizeiro, cv Pérola, obtida para o município de Santa Rita, foi superior à dos demais municípios analisados, inclusive à do município de Sapé, PB, com produtividade adicional em peso de $4.246 \mathrm{~kg} \mathrm{ha}^{-1}$.

O uso da irrigação complementar possibilita um incremento de ganho de peso do fruto do abacaxizeiro, mantidas as demais condições de clima e solo; isto tem evidenciado como as zonas agroclimáticas propícias ao cultivo do abacaxizeiro tornaram o estado da Paraíba um dos principais produtores do País, tanto em termos de produtividade quanto nos aspectos qualitativos do fruto; assim, a diferenciação de peso entre frutos, embora pequena, propicia, quando o abacaxi é comercializado na sua forma in natura, um ganho adicional financeiro satisfatório para o produtor.

Os valores de grau ${ }^{\circ}$ Brix, em torno de 14 , observados no 
Tabela 3. Características dos dados provenientes da última coleta de plantas para análise, com 0 abacaxizeiro, cv. Pérola. Sítio Senhor do Bonfim. Santa Rita, PB, 2001/2002

\begin{tabular}{|c|c|c|c|}
\hline \multicolumn{4}{|c|}{ Variáveis da Planta } \\
\hline Altura da planta $(\mathrm{cm})$ & 115,00 & Peso fresco do caule (g) & 395,00 \\
\hline Diâmetro da planta & 100,00 & Peso fresco das folhas (g) & $3.080,00$ \\
\hline Número de folhas & 43,00 & Peso fresco do pedúnculo (g) & 245,00 \\
\hline $\begin{array}{l}\text { Comprimento do caule } \\
\text { (cm) (aéreo + } \\
\text { subterrâneo) }\end{array}$ & 25,00 & Peso fresco filhotes $(\mathrm{g})$ & $1.096,00$ \\
\hline $\begin{array}{l}\text { Diâmetro do } \\
\text { caule }(\mathrm{cm})\end{array}$ & 5,17 & Peso seco à estufa do caule (g) & 56,61 \\
\hline $\begin{array}{l}\text { Altura de inserção } \\
\text { do fruto }(\mathrm{cm})\end{array}$ & 45,33 & Peso seco à estufa das folhas $(\mathrm{g})$ & 390,82 \\
\hline $\begin{array}{l}\text { Comprimento } \\
\text { do pedúnculo }(\mathrm{cm})\end{array}$ & 42,00 & Peso à estufa do pedúnculo (g) & 28,30 \\
\hline $\begin{array}{c}\text { Diâmetro do } \\
\text { pedúnculo }(\mathrm{cm})\end{array}$ & 2,5 & $\begin{array}{l}\text { Peso seco à estufa } \\
\text { dos filhotes }(\mathrm{g})\end{array}$ & 128,00 \\
\hline Número de filhotes & 9 & $\begin{array}{c}\text { Peso fresco total } \\
\text { da planta sem raiz }(\mathrm{g})\end{array}$ & $6.595,00$ \\
\hline $\begin{array}{l}\text { Comprimento } \\
\text { dos filhotes }(\mathrm{cm})\end{array}$ & 26,60 & $\begin{array}{l}\text { Peso seco total da planta } \\
\text { sem raiz }(\mathrm{g})\end{array}$ & 831,82 \\
\hline \multicolumn{4}{|c|}{ Variáveis do Fruto } \\
\hline Comprimento (cm) & 24 & Comprimento da coroa (cm) & 18,00 \\
\hline Diâmetro (cm) & 10,7 & Peso da coroa $(\mathrm{g})$ & 120,40 \\
\hline $\begin{array}{l}\text { Peso do fruto } \\
\text { com coroa (g) }\end{array}$ & $1.778,33$ & Diâmetro do coração (cm) & 2,40 \\
\hline $\begin{array}{l}\text { Peso seco do fruto } \\
\text { com coroa }(\mathrm{g})\end{array}$ & 228,60 & Sólidos Solúveis Totais ( ${ }^{\circ}$ Brix) & 14,70 \\
\hline Peso do fruto $(\mathrm{g})$ & $1.657,93$ & $\begin{array}{c}\text { Acidez (mLde } \mathrm{NaOH} \\
0,1 \mathrm{~N} / 10 \mathrm{~mL} \text { suco) }\end{array}$ & 4,5 \\
\hline Peso seco do fruto $(\mathrm{g})$ & 212,15 & Número de frutilhos/fruto & 9 \\
\hline
\end{tabular}

Tabela 4. Dados comparativos* de abacaxizeiros cultivados em alguns municípios brasileiros, em condições de irrigação ${ }^{1}$ e de sequeiro ${ }^{2}$

\begin{tabular}{|c|c|c|c|c|}
\hline Características & $\begin{array}{c}\text { Área } \\
\text { experimental, } \\
\text { Santa Rita, PB, } \\
2001 / 2002{ }^{(1)}\end{array}$ & $\begin{array}{l}\text { Sapé, } \\
\text { PB (2) }\end{array}$ & $\begin{array}{l}\text { Sousa, } \\
\text { PB }{ }^{(1)}\end{array}$ & $\begin{array}{c}\text { Mocabinho, } \\
\text { MG }^{(1)}\end{array}$ \\
\hline \multicolumn{5}{|c|}{ Fruto } \\
\hline Comprimento (cm) & 24,00 & 22,00 & 18,00 & - \\
\hline Diâmetro (cm) & 10,70 & 10,60 & 10,60 & - \\
\hline Peso do frruto (cm) & $1.657,93$ & $.573,00$ & $1.296,00$ & 953,00 \\
\hline $\begin{array}{l}\text { Comprimento da } \\
\text { coroa }(\mathrm{cm})\end{array}$ & 18,00 & 14,00 & 14,80 & - \\
\hline Peso da coroa (cm) & 120,40 & 72,00 & 91,00 & - \\
\hline $\begin{array}{l}\text { Diâmetro do } \\
\text { coração }(\mathrm{cm})\end{array}$ & 2,40 & 2,50 & 2,00 & - \\
\hline $\begin{array}{l}\text { Sólidos Solúveis } \\
\text { Totais ( }{ }^{\circ} \text { Brix) }\end{array}$ & 14,70 & 16,00 & 15,10 & $\begin{array}{c}14,00- \\
16,00\end{array}$ \\
\hline $\begin{array}{l}\text { Acidez ( } \mathrm{mL} \text { de } \mathrm{NaOH} \\
0,1 \mathrm{~N} / 10 \mathrm{~mL} \text { de suco) }\end{array}$ & 4,50 & 4,70 & 5,10 & 6,10 \\
\hline \multicolumn{5}{|c|}{ Planta } \\
\hline $\begin{array}{l}\text { Altura de inserção do } \\
\text { fruto }(\mathrm{cm})\end{array}$ & 45,33 & 58,00 & 63,00 & - \\
\hline $\begin{array}{l}\text { Diâmetro } \\
\text { da planta (cm) }\end{array}$ & 72,37 & 75,00 & 77,00 & - \\
\hline Número de filhotes & 9 & 11 & 6 & 6 \\
\hline
\end{tabular}

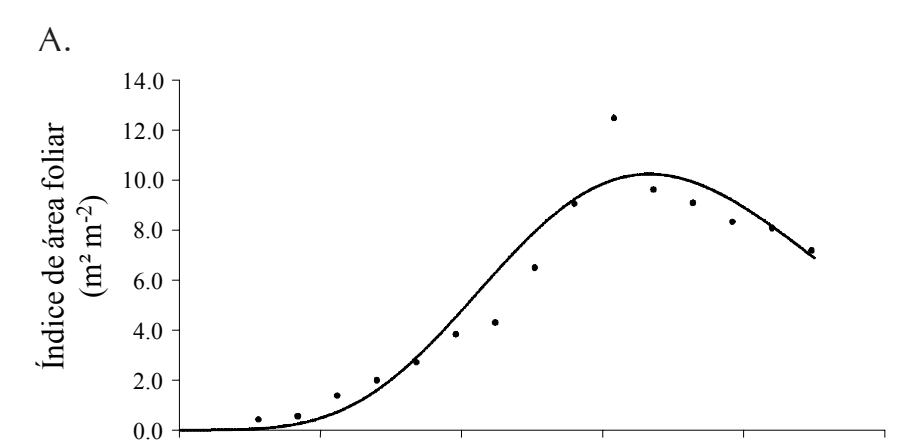

B.

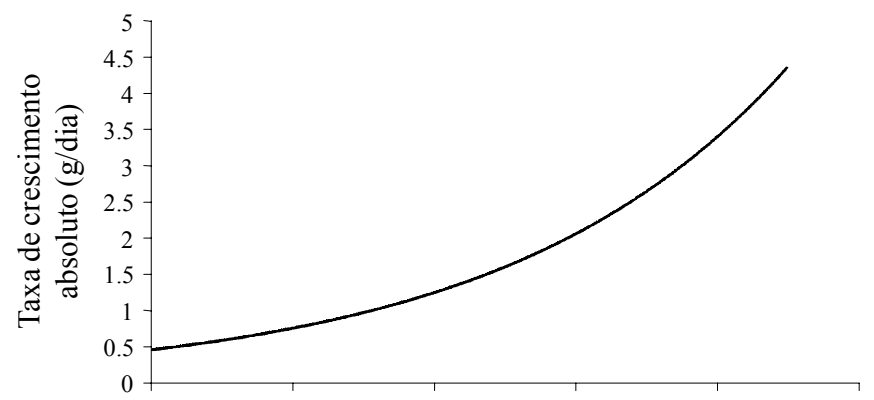

C.
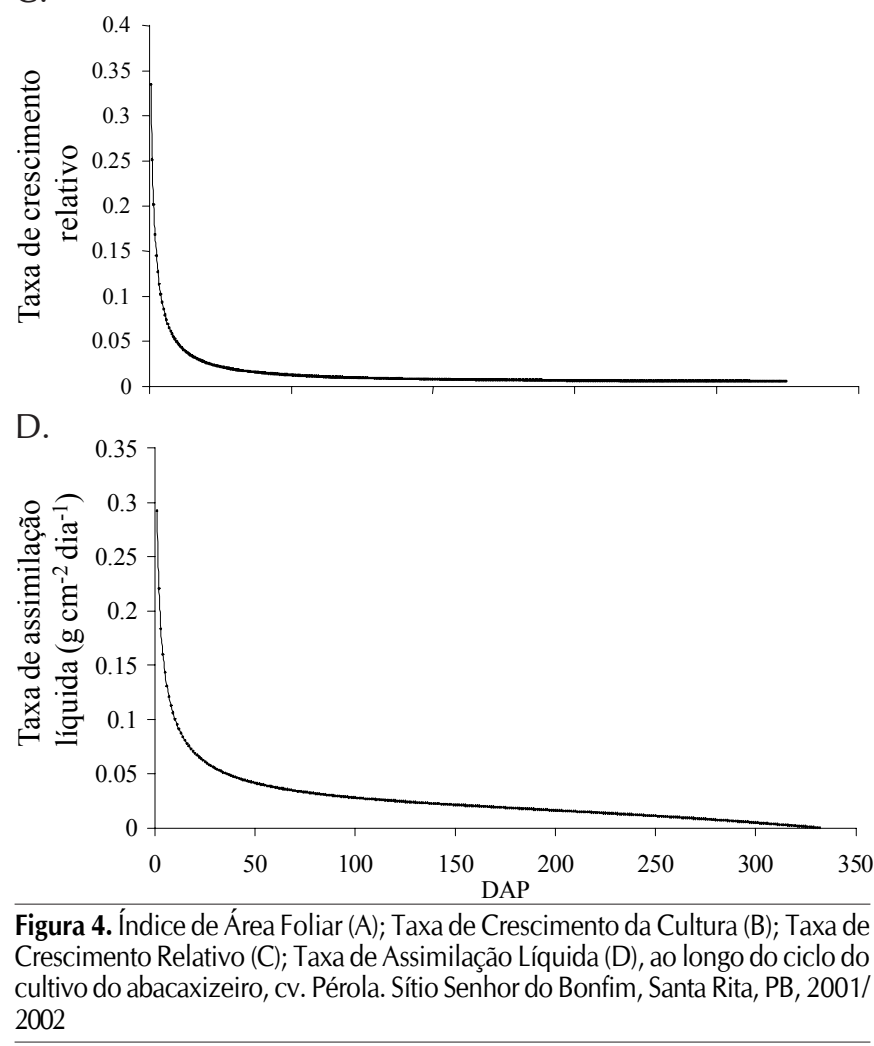

Figura 4. Índice de Área Foliar (A); Taxa de Crescimento da Cultura (B); Taxa de Crescimento Relativo (C); Taxa de Assimilação Líquida (D), ao longo do ciclo do cultivo do abacaxizeiro, cv. Pérola. Sítio Senhor do Bonfim, Santa Rita, PB, 2001/ 2002

abacaxizeiro da área experimental, foram afetados pelas precipitações ocorridas semanas antes da colheita, as quais imossibilitaram o metabolismo sacarino mais apurado.

Na Figura 4 são apresentados os valores dos respectivos fisiológicos: IAF, TCC, TCR e TAL. O IAF atingiu o (Figura 4A).

De acordo com Malézieux (1991) e Bartholomew \& Malézieux (1994), cultivos como a soja e o algodão, entre outros,

R. Bras. Eng. Agríc. Ambiental, v.11, n.2, p.134-141, 2007. 
alcançam um ótimo IAF entre 3 e 4, enquanto o abacaxizeiro pode alcançar IAF superior a 7; entretanto, valores entre 6 e 8 são os mais comuns (Malézieux et al., 2002). Ao longo do experimento o comportamento de TCC pode ser observado na Figura 4B. A TCR, representada na Figura 4C, torna-se decrescente com o passar dos dias do cultivo e estabelece que o crescimento dependerá do material preexistente no início do período e da eficiência da planta na produção de novos produtos fotossintéticos. A TAL (Figura 4D) foi ajustada de forma semelhante ao modelo da TCR, mostrando relação com essa taxa e expressa a taxa fotossintética líquida, em termos de matéria seca produzida (em gramas), por centímetro quadrado de área foliar, por unidade de tempo. De maneira idêntica, a TCR e a TAL apresentam valores elevados inicialmente e, ao passar dos dias, vão diminuindo como resultado provável da translocação de compostos das folhas para outros órgãos da planta como, por exemplo, a inflorescência e o fruto.

\section{CONCLUSÕES}

1. O índice de área foliar alcançou valores superiores aos registrados na bibliografia consultada, tanto em condições de sequeiro quanto em cultivo irrigado.

2. Os frutos do abacaxizeiro alcançaram valores igualmente superiores aos obtidos em outros estudos, seja em termos da massa ou do percentual de valores com massa elevada (60\% dos frutos colhidos alcançaram peso superior a $1,7 \mathrm{~kg}$ ).

3. O rendimento obtido pelo abacaxizeiro nessas condições edafoclimáticas também superou os valores registrados em cultivos de sequeiro e irrigado em outras regiões do País.

\section{AgRADECIMENTOS}

Os autores agradecem a colaboração do Engenheiro Agrônomo João Xavier de Araújo, proprietário do imóvel no qual foi realizado o experimento, e a toda a comunidade do Sítio Senhor do Bonfim - Mumbaba de Belê, em Santa Rita, PB. Em especial, agradecem ao $\mathrm{CNPq}$, pelo apoio financeiro concedido através do Projeto APQ n ${ }^{\circ} 460852 / 00-0$ e pela Bolsa de Produtividade em Pesquisa dos segundo e terceiro autores. São gratos, também, à CAPES, pela concessão de 12 meses de Bolsa de PICDT/UFPB, ao primeiro autor.

\section{LITERATURA CITADA}

Aguiar Neto, A. O.; Rodrigues, J. D.; Nascimento Júnior, N. A. Análise de crescimento na cultura da batata (Solanum tuberosum ssp Tuberosum) submetida a diferentes lâminas de irrigação: razão tubérculo-parte aérea, área foliar específica, razão de área foliar e razão de massa foliar. Irriga, Botucatu, v.4, n.1 p. 13-24, 1999.

Ayers, R.S.; Westcot, D.M. A qualidade da água na agricultura: Campina Grande: UFPB, 1991. 218p.
Barreiro Neto, M.; Choairy, S.A.; Lacerda, J.T. Carvalho, R.A.; Oliveira, E. F. Caracterização do abacaxizeiro Pérola no Estado da Paraíba. Pesquisa Agropecuária. EMEPA, João Pessoa, n.10, p.33-39, 1998.

Bartholomew, D.P.; Malézieux, E.P. Pineapple. In: Schaffer, B.; Andersen, P.C.; ed. Handbook of environmental physiology of fruits crops: Sub tropical and tropical crops. Boca Raton: CRC Press, v.2, Cap. 11, p. 243-291, 1994.

Carvalho, R.A.; Lacerda, J.T. de; Oliveira E.F. de; Choairy, S.A.; Barreiro Neto. M. Abacaxicultura irrigada no semi-árido Paraibano. João Pessoa: Empresa Estadual de Pesquisa Agropecuária da Paraíba S/A, 2001, 29p. Documentos 32

Coppens D'eeckenbrugge, G.; Leal, F. Morphology, anatomy and taxonomy. In: Bartholomew, D. P.; Paull, R. E.; Rohrbach, K. G. (Ed.) The pineapple: Botany, production and uses. New York: CAB International, 2003. p.13-32.

Cunha, G.A.P. Implantação da cultura. In: Cunha, G.A.P.; Cabral, J.R.; Souza, L.F. da S. (ed.) O abacaxizeiro: Cultivo, agroindústria e economia. Brasília: Embrapa Comunicação para Transferência de Tecnologia, 1999, 480p.

Cunha, G.A.P. da; d'Oliveira, L.O.B. Avaliação agro-econômica do abacaxizeiro na bacia do sub-médio São Francisco. Cruz das Almas: Embrapa-CNPMF. 1993, 2p. Abacaxi em foco, 105

Cunha, G.A.P. da; Rocha, S.L. Comportamento de cultivares de abacaxi sob irrigação no Norte de Minas Gerais. Cruz das Almas: Embrapa - CNPMF, 1993. 2p. Abacaxi em foco, 95

EMBRAPA - Empresa Brasileira de Pesquisa Agropecuária. Centro Nacional de Pesquisa de Solos. Sistema Brasileiro de Classificação de Solos. Brasília: CNPS, 1999, 412p.

Malézieux, E. Recherche de relations entre la biomassa aérienne, la surface foliaire et I'interception du rayonnement solaire chez l'ananas. Fruits, Paris, v.46, p.523, 1991.

Malézieux, E.; Côte, F.; Bartholomew, D.P. Crop environmental, plant growth and physiology. In: Bartholomew, D.P.; Paul, R.E.; Rohrbach, K.G. The pineapple: botany, production and uses. Hononulu: (ed.) University of Havaii, 2002. 320 .

Oliveira, R. A.; Daros, E.; Zambon, J. L. C.; Weber, H.; Ido, O. T.; Zuffellato-Ribas, K. C.; Koehler, H. S.; Silva, D. K. T. Crescimento e desenvolvimento de três cultivares de canade-açúcar, em cana-planta, no Estado do Paraná: Taxas de crescimento. Scientia Agrária, v.6, n.1-2, p.47-53, 2005.

Razzaque, A. H. M; Hanafi M. M. Effect of potassium on growth, yield and quality of pineapple in tropical peat. Fruits, Paris, v.56, p.45-49, 2001.

Reinhardt, D. H. R.; Cabral, J. R. S.; Souza, L. F. S.; Sanches, N. F.; Matos, A. P. Pérola and Smooth Cayenne pineapple cultivars in state of Brazil: growth, flowering, pediseases, yield and fruit quality aspects. Fruits, Paris, v.57, p.43-53, 2002.

Reinhardt, D.H.R.; Medina, V.M. Crescimento e qualidade do fruto do abacaxi cvs. Pérola e Smooth Cayenne. Pesquisa Agropecuária Brasileira, Brasília, v.3, p.435-447, 1992. 
Silva, L.C.; Beltrão, N.E.de M.; Amorim Neto, M. Análise de crescimento de comunidades vegetais. Campina Grande: Embrapa-CNPA, 2000. 46p. Circular Técnica, 34

Souza, L.F.S; Exigências Edáficas e Nutricionais. In: Cunha, G.A.P.; Cabral, J.R.; Souza, L.F. da S. O abacaxizeiro: Cultivo, agroindústria e economia. Brasília: Embrapa Comunicação para Transferência de Tecnologia, 1999. 480p.
Vilar, L. da C; Classificação do abacaxi (Ananas comosus (L) Merril). Programa brasileiro para melhoria dos padrões comerciais e embalagens. Centro de Qualidade em Horticultura. São Paulo: CEAGESP, 2000. "folder” Elaboração Técnica

Zhang, J.; Bartholomew, D.P. Effect of plant population density on growth and dry matter partitioning of pineapple. Acta Horticultura, Trois-Ilets, 1997. v.425, p.363-376, 1997. 